\title{
A TRAJETÓRIA DA ADMINISTRAÇÃO DA EDUCAÇÃO PÚBLICA NO BRASIL E A CONSTRUÇÃO DA DEMOCRACIA
}

\author{
Nadia Pedrotti Drabach ${ }^{1}$ \\ Universidade Federal do Paraná - UFPR
}

\section{RESUMO}

Este trabalho tem por objetivo analisar os diferentes modelos de gestão educacional no Brasil, ao longo do século XX, relacionando-os com o contexto histórico e com as mudanças conjunturais. Para a materialização desta proposta o estudo buscou, em bibliografia pertinente, elementos que possibilitaram construir interpretações e relações entre si, de maneira a responder o propósito do trabalho. $\mathrm{O}$ modelo de administração da educação presente nas primeiras décadas do século XX se baseava nos princípios da administração geral e possuía uma estreita relação com o contexto socioeconômico da época. Os anos 1980 trouxeram novos discursos para o campo da administração da educação que se inseriram no movimento pela democratização da sociedade que acabava de sair do regime ditatorial. A inserção do princípio da gestão democrática da educação na Constituição Federal de 1988 significou um avanço significativo na construção da gestão democrática da educação. Entretanto, a década de 1990 não foi tão promissora em termos da construção da sociedade democrática almejada na década anterior o que trouxe reflexos para o campo da administração da educação.

Palavras-chave: administração da educação; políticas educacionais; gestão democrática.

\section{THE TRAJECTORY OF ADMINISTRATION PUBLIC EDUCATION IN BRAZIL AND CONSTRUCTION OF DEMOCRACY}

\begin{abstract}
The present paper aims to point out some elements that allow historic relations between the configuration of a particular model of society and the development of guidelines which educational administration had at different times in Brazil. To materialize this proposal, the study looked at relevant literature, elements that allowed constructing interpretations and relationships between them, in order to answer the purpose of work. The model of educational administration in the early decades of this century based on the principles of general management and has a close relationship with the socio-economic context of the time. The 1980s brought new discourses in the field of educational administration which fall within the movement for the democratization of society just out of the dictatorial regime. The inclusion of the principle of democratic management of education in the Federal Constitution of 1988 represented a significant advance in the construction of democratic management of education. However, the 1990 was not as promising in terms of building the democratic society desired in the previous decade which brought significant impact to the field of educational administration.
\end{abstract}

Keywords: educational administration, educational policies, democratic management. 


\section{Introdução}

A década de 1930 no Brasil foi caracterizada por grandes transformações no campo educacional. Nesse momento da história a sociedade brasileira avançava no processo de industrialização. A população deixava, aos poucos, de ser predominantemente rural tornando-se cada vez mais urbana com o crescimento das cidades, em decorrência do desenvolvimento industrial. $\mathrm{O}$ modelo de educação tradicional já não respondia às exigências da sociedade que se transformava. O novo cenário no campo da educação configurou-se por influência, principalmente, dos ideais da Escola Nova ${ }^{2}$, protagonizados pelo educador norte americano, John Dewey.

Estes novos ideais de educação são resultado, em parte, das mudanças ocorridas no campo econômico, político e cultural durante no final século XIX e início do XX com a ascensão da sociedade industrial européia, que, aos poucos, foi tomando dimensões maiores, espalhando-se pelos demais continentes. Essa nova configuração social demandava também, uma nova forma de compreender a educação. $\mathrm{O}$ desenvolvimento científico no campo da psicologia e medicina, principalmente, forneceram as bases para o desenvolvimento da racionalidade pedagógica, capaz de combinar características individuais e exigências sociais, respondendo as demandas do sistema.

Diante desse contexto, as ideias que moviam intelectuais brasileiros a pensar uma nova educação, segundo Lemme (2005) eram impulsionadas, por um lado, pelas condições objetivas, caracterizadas pelas transformações sociais, políticas e econômicas da época. Por outro lado, eram influenciados pelo conjunto de ideias vindas da Europa que pregavam a renovação de métodos e processos de ensino que vinham na contramão da "velha pedagogia Jesuítica" o chamado movimento escolanovista, já descrito anteriormente.

As críticas ao modelo tradicional de educação e as novas aspirações destes educadores brasileiros resultaram no documento que ficou conhecido como "O Manifesto dos Pioneiros da Educação Nova". Neste documento é possível identificar características fundamentais como: um modelo de educação baseado no respeito ao desenvolvimento individual; a educação como um direito de todos dentro do princípio democrático da igualdade de oportunidades para todos; o direito a educação deve ser assegurado pelo Estado, por isso esta deve ser essencialmente pública; por ser democrática, a educação deverá ser única, obrigatória, gratuita e laica; na organização dos serviços e dos sistemas de educação e ensino adota-se o princípio da descentralização administrativa. É nesse contexto que surgem os primeiros escritos sobre administração da educação.

\section{As raízes da administração escolar no Brasil}

No campo da administração escolar a grande questão que embasava os discursos dos intelectuais era a necessidade de cientifização da educação e a ampliação da oferta educacional, alimentada pelo desejo da erradicação do analfabetismo que apresentava elevadas taxas e constituía a "vergonha nacional" que uma vez eliminada "colocaria o país pari passu ${ }^{3}$ com o mundo desenvolvido, seja porque aumentaria o número de votantes, seja porque alguns grupos populares já haviam compreendido a alfabetização como instrumento político" (GIORGI, 1992, p. 56).

O movimento reformista que tomava corpo nas décadas de 1910 e 1920 superestimava as possibilidades de intervenção do processo educativo, de tal forma que nele eram depositadas as soluções para os problemas sociais, econômicos e políticos do país (SHIROMA; MORAES; EVANGELISTA; 2007).

No Manifesto dos Pioneiros da Escola Nova, a crítica à falta de espírito científico na administração escolar se definia como a principal causa da desorganização do sistema 
de ensino. Dessa forma, buscava-se a construção de um modelo de administração que, embasado em princípios científicos, garantisse a eficácia do ensino. Surgem, neste contexto, os primeiros escritos sobre a administração escolar no Brasil, protagonizados, em sua maioria, pelos próprios educadores participantes do Manifesto.

Segundo Drabach (2009):

Dentre as condições que favoreceram estes escritos, uma delas foi a criação da cadeira de Administração Escolar na Universidade de São Paulo (USP) e no Instituto de Educação do Rio de Janeiro. Na USP, Roldão Lopes Barros foi o primeiro professor da referida disciplina, sendo o introdutor das idéias de Henry Fayol nos estudos de Administração Escolar. Embora não tenha produzido nenhum escrito sobre o tema, foi orientador do trabalho de José Querino Ribeiro: Fayolismo na Administração das escolas Públicas (1938). Tempos depois, Querino Ribeiro elabora outra obra, Ensaio sobre uma teoria de Administração Escolar (1953), resultante da tese defendida ao ingressar como professor na Cátedra de Administração Escolar e Educação Comparada, na Universidade de São Paulo ( DRABACH, 2009, p.19):

Além de Querino Ribeiro, destacaram-se também Carneiro Leão, Lourenço Filho e Anísio Teixeira como protagonistas dos primeiros escritos de administração escolar no Brasil, cujas produções contribuíram para a definição dos contornos administrativos da educação naquela época.

Com o aumento da oferta educacional, a organização da educação tornava-se cada vez mais complexa exigindo um olhar atento para as questões administrativas que começavam a inspirar-se na abordagem clássica de administração ${ }^{4}$, aquela aplicada às empresas. Carneiro Leão, inspirado no modelo de administração empresarial, movimento fayolismo nascido na França, defendia a administração voltada para operações técnicas e de organização sistemática e fiscalizadora de todos os espaços e ações dentro da escola, de forma que esta se desenvolvesse em harmonia.

O pensador idealizou um modelo de administração escolar extremamente hierarquizado e centralizado na figura do diretor. Este deveria ser uma pessoa muito preparada intelectualmente, trazendo em sua bagagem conhecimentos administrativos, pedagógicos e educacionais de forma geral. O diretor devia ser defensor das políticas educacionais mais amplas, pois seu papel dentro da escola, além de dirigir é de um representante legal do Estado. Leão, apesar de defender a origem pedagógica da administração escolar, enfatizava em seus objetivos os aspectos administrativos. Segundo Souza (2007):

Uma hipótese que pode auxiliar a explicar tal postura é a de que, para o autor, a origem da função do diretor escolar é pedagógica, como de resto é todo o objetivo do seu trabalho, todavia, para buscar tais objetivos, o diretor opera no campo administrativo e de representação política do poder instituído (SOUZA, 2007, p. 30).

Em síntese, a administração escolar conforme foi idealizada por Carneiro Leão, se centrava na figura do diretor que era o responsável por planejar as diretrizes gerais da educação e por organizar o grupo de professores e técnicos que tinham a função de colocar em prática as políticas educacionais. Na concepção de Carneiro Leão: “o papel pedagógico do diretor está justamente em desenvolver ações administrativas voltadas a garantir as condições para o funcionamento das ações pedagógicas" (SOUZA, 2007, p. 30).

Assim como Leão, José Querino Ribeiro via a aplicação da administração escolar como algo necessário para assegurar a unidade educacional. Para o mesmo, a 
administração deveria atender, sobretudo, a uma filosofia e a uma política de educação. Os princípios de administração defendidos por Ribeiro são: os objetivos e ideais de educação que representam as razões pelas quais se educa; os meios através dos quais se alcançarão os objetivos, que são as políticas adotadas pela educação; os fundamentos da educação baseados especialmente nos pressupostos dos ideais da Escola Nova: liberdade, unidade, economia, flexibilidade. Outro princípio fundamental da teoria de Ribeiro é o estudo da administração geral. O mesmo inspirava-se nos princípios administrativos da teoria de Taylor e Fayol, embora criticasse alguns de seus aspectos (RIBEIRO, 1986).

Ribeiro atribui uma grande importância aos princípios da administração geral. Ele afirma que a administração escolar é uma das formas de aplicação da administração geral. Assim, defendia a divisão do trabalho na escola (princípio da teoria de Taylor), organização do currículo em disciplinas, por exemplo. Porém, enfatizava que a administração deveria agir de forma a garantir a unidade no trabalho, princípio da teoria de Fayol, que destacava a importância da unidade de comando.

Outro teórico que pensou a administração escolar nesse contexto foi Lourenço Filho. Diante da necessidade de formação do trabalho para a indústria, o autor defendia que a educação deveria ter relação com o perfil de trabalhador que se pretendia formar. A escola deveria produzir algo em quantidade e em qualidade (LOURENÇO FILHO, 2007). Dada a complexidade que envolve o contexto escolar, Lourenço Filho salientava a importância de abandonar o caráter experimental e intuitivo que caracterizava a administração até então, para adquirir maior cientificidade e racionalidade, em concordância com o espírito administrativo geral da época.

De acordo com Lourenço Filho (2007), uma atividade complexa como a administração escolar requer, para o melhor funcionamento, a distribuição de tarefas, ou seja, a divisão do trabalho que, em sua opinião, necessita de organização para que possa construir um fim determinado.

Administração e organização na visão do autor servem como meio para tornar as instituições mais eficientes e não como um fim em si mesmas. Em relação à proposta de administração escolar de Carneiro Leão e Querino Ribeiro, Lourenço Filho (2007) agrega um elemento novo, que reflete a sua formação em psicologia, a ideia de comportamento administrativo, dando destaque ao papel das relações humanas na concretização dos objetivos educacionais. Dessa forma, ao administrador escolar cabe também gerir as relações dentro da escola, ajustando-as entre si, tornando-a solidárias e participativas na execução de objetivos comuns, embora não tenham participado da elaboração. Essa valorização das relações dentro da escola não rompe com a ideia de hierarquização, que, de acordo com Lourenço, está organizada em quatro níveis: alunos, mestres, diretores e chefes de órgão de maior alcance.

Outro pensador que se ocupou em pensar a administração escolar nessa época foi Anísio Teixeira. Diferente dos outros três autores, Anísio criticava a aplicação direta da estrutura da administração geral à educação em função de que essas duas formas de administrar visam a concretização de objetivos diferentes. Na fábrica o mais importante é o produto final e a humanização está no ajuste do processo de trabalho. Na escola o mais importante é a formação humana do aluno, algo que envolve maior complexidade.

O autor salienta a importância de três funções administrativas dentro da escola: o administrador escolar, o supervisor de ensino e orientador ou guia dos alunos. Na sua visão somente o professor é capaz de exercer estas funções na escola. $\mathrm{O}$ autor, na sua forma de pensar a administração escolar, tirava do centro a figura do diretor, destacando o próprio processo educativo como central. A função de quem administra nada mais é do que oferecer o suporte para que a aprendizagem aconteça (TEIXEIRA, 1961). 
Diante da expansão dos estabelecimentos escolares, Anísio Teixeira, preocupava-se com a qualidade do ensino. Para ele, mais importante do que ter um grande número de crianças na escola é garantir o processo de aprendizagem de todas. Com a introdução destas ideias administrativas começa o romper-se a aplicação dos princípios da administração geral baseados na teoria taylorista/fordista e inicia uma mudança na forma de pensar a administração escolar (DRABACH, 2009).

No entanto, com o regime de governo ditatorial, estas ideias que conduziam para um avanço na forma de compreender a administração da educação, trazidas por Anísio Teixeira, ficaram estagnadas. Durante o período político-econômico ditatorial, vivido no país entre as décadas de 1960 a 1980, o modelo de administração escolar utilizado era pautado nas teorias da Administração Geral e empregado como instrumento de controle e punição nos espaços escolares. O planejamento educacional era realizado de forma burocrática, elaborado por especialistas e por organismos internacionais através de acordos realizados entre o Ministério da Educação (MEC) e a United States Agency for International Development (USAID).

Estes acordos visavam à criação de convênios de assistência técnica e cooperação financeira à educação brasileira. O período histórico da realização dos acordos é fortemente marcado pelo tecnicismo educacional no qual a educação é concebida como pressuposto de desenvolvimento econômico. $\mathrm{O}$ apoio internacional tinha por objetivo o estabelecimento de diretrizes políticas e técnicas que visavam à adequação do sistema educativo às exigências do capitalismo internacional.

As produções científicas mais significativas a partir da década de 1950 traziam implícitas ou explicitamente as configurações da administração escolar baseada no modelo empresarial que se caracterizava pelo predomínio da técnica e da divisão do trabalho. Dessa forma, os escritos mais significativos sobre administração escolar que se preocupavam com as especificidades desta função na escola foram as produções dos Pioneiros.

Um exemplo do caráter tecnocrático da administração da educação foi a implantação, durante a Ditadura Militar do currículo que articulava o sistema escolar com o mercado de trabalho tornando o ensino de segundo grau compulsoriamente profissionalizante, oferecendo a formação técnica em três áreas do mercado em desenvolvimento: industrial, comercial e de serviços (LEDESMA, 2008). O que, de acordo com Cunha e Góes (1994), era uma forma de conter a procura pelo ensino superior. Em relação ao ensino superior a preocupação estava no aprimoramento científico, com a eficiência e a produtividade, características que, segundo a autora, estão em consonância com o grupo que assumiu o governo a partir de 1964, composto por militares e tecnocratas.

Com o fim do governo ditatorial surgem novos anseios sociais, a luta pela democracia e a liberdade de pensamento que imprimem suas marcas também no campo educacional.

\section{A gestão democrática da educação na Constituição de 1988}

A Constituição Federal de 1988 foi elaborada em um contexto marcado pela necessidade de democratização do país, que acabava de sair do regime de governo ditatorial. A época caracteriza-se pelo surgimento dos primeiros movimentos grevistas, a luta pela liberdade de organização partidária, o movimento "Diretas já", entre outras ações no campo político e social que configuravam um clima de maior participação no país e encaminhavam, inclusive, para uma nova forma de organização do Estado (ADRIÃO; CAMARGO, 2007). 
Juntamente com a grave crise econômica que atingia o país no final do regime militar, causada pelo desequilíbrio financeiro e o crescimento da dívida externa, surgiam sinais de esperança e perspectivas de democratização do país. Porém, na Nova República, que iniciava em 1985, a crise, além de econômica era também marcada pelo desencanto e a incerteza diante das contradições e insucessos do governo Sarney ${ }^{5}$, primeiro presidente a assumir o cargo após a ditadura. O caráter autoritário e centralizador que caracterizou a ditadura no Brasil, entre os anos 1964 e 1985, passou a ser questionado pelos movimentos populares e sindicais com vistas na construção de uma forma de governo, transparente, com instâncias de participação, sujeito a um maior controle público e atento às demandas sociais. Essas reivindicações se inscreveram no plano das reformas democráticas do Estado brasileiro, cuja preocupação estava em materializar, na esfera legislativa, o conteúdo democrático.

Dessa forma, a Constituição Federal de 1988 se configurava tendo como base os anseios de uma sociedade sedenta de mudanças e que lutava pela construção de um país democrático. Os direitos sociais e individuais assegurados na Lei dão a ela um caráter positivo, passando a ser considerada a Constituição mais cidadã que o Brasil já teve. Em relação aos direitos individuais, a Constituição assegura o acesso de todos às informações fornecidas pelos órgãos públicos, de interesse individual ou coletivo, tratado no inciso XXXIII do art. $5^{\circ}$ (BRASIL, 1988). Em relação aos direitos sociais, no art. $10^{\circ}$ a Constituição garante a todos os trabalhadores e empregadores a participação em órgãos colegiados que tratem de assuntos de seus interesses (BRASIL, 1998). A participação de representantes de diferentes setores em órgão da administração pública também é um direto garantido na Constituição. Além destes, o direito à educação é assegurado nos termos na Lei.

Em decorrência do processo de redemocratização do país no final dos anos 1980, no campo educacional também se inseriam ideias democráticas que partiam de um movimento crítico que reivindicava mudanças, dentre elas, foi introduzido na Constituição Federal o princípio de gestão democrática do ensino (ADRIÃO e CAMARGO, 2007).

No entanto, é preciso destacar que a introdução deste princípio na Constituição Federal rendeu alguns debates em torno do sentido que este deveria atribuir à gestão da educação. Este debate deu-se entre dois grupos principais. O primeiro, constituído por entidades de caráter nacional e identificado com a defesa da Escola Pública, mostrava-se adepto à participação da comunidade local na gestão educacional e escolar. Esta defesa baseava-se no entendimento de que para a construção de uma sociedade democrática a educação constituía-se no principal pilar. Portanto, a participação no cotidiano escolar seria o começo para a aprendizagem da democracia que se queria construir na esfera maior da sociedade.

O segundo grupo, ligado aos interesses privados, composto por representantes do empresariado educacional e das escolas confessionais, se opunha ao posicionamento do primeiro, em relação à ideia de gestão. Para estes, a participação se resumia na colaboração de alunos, famílias e professores com a direção das escolas ou mantenedoras dos estabelecimentos de ensino e não na tomada de decisões no âmbito da gestão escolar.

No texto do anteprojeto da Constituição o conceito de gestão incorporado foi o do primeiro grupo, porém teve sua formulação alterada e apoiada pelos setores conservadores. De acordo com Adrião e Camargo (2007) o texto alterado ganhou um sentido redundante e restritivo, passando a ter a seguinte redação: "gestão democrática do ensino público na forma da lei" (BRASIL, 1988).

O conceito de gestão escolar ficou restrito ao ensino público, excluindo a gestão democrática do ensino privado. A expressão "na forma da lei" protelou a 
operacionalização da gestão democrática para um segundo momento, quando da elaboração de leis complementares, a Lei de Diretrizes e Bases da Educação Nacional Lei 9394/96, por exemplo. Dessa forma, a permanência da gestão democrática do ensino público na Constituição, representou uma conquista parcial, na medida em que sua abrangência tornou-se limitada e sua aplicação adiada.

A década de 1980, no Brasil foi marcada pela rearticulação dos movimentos sociais cuja principal reivindicação era a democratização do país. No campo educacional ${ }^{6}$, desde o início dos anos 1980 já havia manifestações também nesse sentido, indicando a necessidade de uma reestruturação na lógica da organização dos sistemas de ensino atendendo a demanda por democracia. Nas palavras de Adrião:

Desde o início da década de 1980, no Brasil, a reivindicação por eleições de diretores foi defendida por educadores e sindicatos como meio para a superação de práticas clientelistas na indicação dos dirigentes de escola, como forma de romper com a lógica meritocrática, dos concursos públicos que prescindiam da opinião de usuários e funcionários para a escolha do diretor da escola, ou ainda como maneira de superar o modelo de organização e gerência do trabalho presente nas escolas, o qual se pautava na lógica hierárquica e, portanto, centralizadora dos processos decisórios, própria das organizações burocráticas (ADRIÃO, 2006 p. 56)

A necessidade de um redirecionamento na organização da estrutura escolar se dava em defesa de uma administração coletiva da escola, com a participação da comunidade nas tomadas de decisão, na elaboração de metas para o ensino em cada unidade escolar e a exclusividade do financiamento da escola pública pelo poder público. Em síntese, as mudanças indicavam o caminho da democratização da gestão escolar e educacional (ADRIÃO, 2006).

\section{A LDB Lei n 9394/96 e a Gestão Democrática}

A década de 1990, não foi tão promissora em termos dos avanços democráticos gestados na década de 1980 . Isso porque, um novo projeto de sociedade começava a se constituir a partir de orientações neoliberais, ameaçando a concretização dos ideais democráticos.

A partir das eleições presidenciais de 1989 definem-se os rumos da sociedade para os próximos anos. Segundo Coutinho (2002), o país colocava-se diante de dois modelos de sociedade ocidental, uma do tipo "americana" e outra "européia". A primeira marcada pela despolitização. Nesse modelo de sociedade, as lutas sindicais se dão a partir de interesses restritos: reivindicações por melhores salários, por exemplo. Já a segunda, apresenta uma organização social em termos políticos, em que as organizações ultrapassam o modelo econômico-corporativo para um momento ético-político universalizador. Este tipo de sociedade, na visão do autor, foi a que permitiu à Europa a construção de um Estado de Bem Estar Social ${ }^{7}$ incomparável.

Na concorrência pela Presidência da República na época tínhamos, de um lado, Fernando Collor de Mello (PRN), que trazia uma proposta de sociedade neoliberal e se identificava como o modelo americano e Lula (PT) que defendia uma proposta de ampliação do espaço público, distribuição de renda e participação popular, representante segundo Coutinho (2002) do modelo europeu de sociedade.

Nas palavras de Arelaro:

[...] a década de 1990 inicia-se com dois movimentos aparentemente contraditórios e fortes: de um lado, o desejo de implementação dos 
direitos sociais recém-conquistados e a defesa de um novo projeto político- econômico para o Brasil, presentes especialmente nas propostas de governos municipais progressistas, eleitos em 1989; de outro, a assunção de Fernando Collor de Mello, na presidência da República, com um discurso demagógico de defensor dos 'descamisados' (os pobres) contra os 'marajás' (os ricos) e um projeto de caráter neoliberal, traduzindo o 'sentimento nacional' de urgência de reformas do Estado para colocar o país na era da modernidade (ARELARO, 2000, p.96).

Com Collor no poder "deflagrou-se o processo de ajuste da economia brasileira às exigências da reestruturação global da economia. A imagem populista e moralizante que caracterizou a campanha Collor, foi desmascarada pelo estilo modernizador e intervencionista que se iniciou pela privatização de empresas estatais e marcou a sua gestão até o momento de sua interrupção pelo Congresso Nacional em 1992" (SHIROMA; MORAES; EVANGELISTA, 2007, p. 46).

Assume em seu lugar o vice-presidente Itamar Franco que, diferente do seu antecessor, desacelerou o processo de privatização. No entanto, o projeto neoliberal vai se consolidando, ajudado por pressão das agências internacionais que monitoram os empréstimos financeiros no país, especialmente o Banco Mundial ${ }^{8}$ e o Fundo Monetário Internacional (FMI) (ARELARO, 2000).

Em 1990, realizou-se a Conferência Mundial de Educação para Todos, em Jomtien na (Tailândia), esse evento contou com o financiamento de órgãos internacionais como a Unesco, a ONU (Organização das Nações Unidas para a Educação a Ciência e a Cultura), o Unicef ( Fundo das Nações Unidas para a Infância), o PNUD (Programa das Nações Unidas para o Desenvolvimento) e o Banco Mundial. Os países participantes da Conferência comprometeram-se em assegurar uma educação básica de qualidade às crianças, jovens e adultos.

Segundo Arelaro (2000), o mérito da Conferência estava em colocar a educação básica no centro das atenções mundiais, destacando sua importância e prioridade. O projeto de Educação para Todos compreendia que a educação deveria realizar as Necessidades Básicas de Aprendizagem (NEBAS) de crianças jovens e adultos. Como necessidades básicas destacam-se as seguintes situações: a sobrevivência; o desenvolvimento pleno de suas capacidades; vida e trabalho dignos; participação plena no desenvolvimento; melhoria da qualidade de vida; tomada de decisões informadas; a possibilidade de continuar aprendendo, entre outras.

Um aspecto importante a ser ressaltado e que fica evidente quando são destacadas as necessidades básicas de aprendizagem é a compreensão de Educação Básica que não se resumia somente na educação escolar. No Brasil, tendo em vista a polêmica que envolveu o conceito de educação básica na própria conferência, considerou-se como parte do projeto de Educação para Todos, apenas o Ensino Fundamental.

O Projeto Educação para todos definiu como tempo de implementação de suas metas, o período de 10 anos (1990-2000). Dentre os propósitos do projeto estavam: a prioridade da educação feminina; a educação especial; foco na aprendizagem e na avaliação dos resultados; garantia de condições materiais para a aprendizagem de crianças jovens e adultos; o envolvimento do Estado e também da sociedade em garantir uma educação de qualidade. Em 2000 foi realizado o Fórum de Educação para Todos, realizado em Dakar/Senegal que retomou os princípios definidos na conferência de Jomtien. De acordo com os resultados apresentados no relatório da UNESCO, o Brasil está longe de alcançar os propósitos, especialmente no aspecto da qualidade da educação básica. 
A Lei de Diretrizes e Bases da Educação Nacional (LDB) gestada ao longo da década de 1990 traz implícitos os princípios neoliberais e torna-se uma contra reforma ao princípio democrático definido na Constituição Federal de 1988. Segundo Arelaro (2000), os primeiros cinco anos da década de 1990, mesmo que influências do mercado internacional já se façam perceber na organização do Estado Brasileiro, os princípios democráticos assegurados na Constituição de 1988 são preservados, especialmente a questão da cidadania que orientava a formulação dos direitos sociais e dos projetos educacionais.

A partir de 1995, durante o governo Fernando Henrique Cardoso, o conceito de gestão democrática passa por modificações, há uma redefinição do conceito de gestão que provocou influências significativas nas políticas educacionais que se delinearam a partir daí. De acordo com Paro (2007), o primeiro aspecto a ser analisado na LDB de 1996 é a restrição do caráter democrático ao ensino público, o que significaria dar liberdade ao ensino privado de levar em conta ou não o princípio democrático garantido pela constituição. Significa inclusive, colocar em xeque a ideia de construção de uma sociedade democrática.

Nas palavras de Paro (2007):

Por aqui dá para perceber a que disparates nossos legisladores se prestam, quando, cedendo à ânsia do lucro representada nos lobbies dos interesses privados, permitem que a lógica do mercado se sobreponha à razão e aos interesses da sociedade (PARO, 2007, p.74).

O segundo aspecto que pode ser destacado em relação ao princípio democrático é que o mesmo se esgota no âmbito nacional e a responsabilidade de sua aplicação é repassada aos sistemas de ensino, o que significa dizer que caberá aos estados e municípios a decisão sobre colocar em prática ou não, aspectos muito importantes do princípio da gestão democrática, como a escolha dos dirigentes escolares, por exemplo. Pode-se aferir aqui que a questão da democracia na educação, de acordo com a LDB se resume ao âmbito da escola, quando deveria ser garantido também em instâncias maiores da organização do Ensino.

O artigo $14^{\circ}$ da LDB assegura princípios que já vinham sendo implementados nos sistemas de ensino como a participação dos professores na elaboração do projeto pedagógico das escolas e a constituição de conselhos escolares com a participação da comunidade. Dessa forma, a Lei não traz nenhum avanço, apenas legitima o que já vinha acontecendo (PARO, 2007).

Sobre as condições de trabalho na escola, segundo Paro (2007), os artigos $4^{\circ}$ e $25^{\circ}$ da LDB/96 trazem subsídios importantes e que podem embasar reivindicações no sentido da construção democrática na escola. Os mesmos garantem condições mínimas de trabalho e de construção da qualidade do ensino, por exemplo, a adequação do número de alunos, respondendo as exigências didáticas pedagógicas, carga horária, condições materiais dos estabelecimentos de ensino. Contudo, estas possibilidades são pouco explícitas o que acaba limitando ou retardando a concretização de práticas democráticas no espaço educacional.

\section{Considerações finais}

É possível observar, ao longo do século XX no Brasil, uma estreita relação entre o modelo de educação e as mudanças socioeconômicas e políticas em diferentes épocas. $\mathrm{Na}$ década de 1930 o modelo de educação proposto estava em consonância com o desenvolvimento industrial que marcou aquela época. Na década de 1990 a educação "assume uma dimensão redentora, à medida que se torna requisito fundamental para o 
ingresso do Brasil no mercado competitivo da economia global" (SOUZA; SILVA, 2009, p.783). Assim, observa-se que a educação no Brasil ao longo do século XX apresentou-se como um campo de disputa política e ideológica e como espaço-base para a implementação de um determinado modelo socioeconômico.

A Constituição de 1988 e a LDB de 1996 legitimaram o princípio da gestão democrática da educação, delegando aos sistemas e às escolas a adoção de mecanismos que favoreçam a construção desse modelo de gestão. Dessa forma, através do processo educativo torna-se possível a configuração de uma base para a construção de um país mais democrático, uma vez que a criação de espaços de participação e envolvimento da comunidade escolar nas decisões que ocorrem na escola tendem a ser difundidas em outros espaços sociais. Contudo, ainda há um longo caminho a percorrer no sentido da expansão desse modelo de gestão no interior das escolas e dos sistemas educacionais. As práticas mais ou menos democráticas que acontecem nas instituições de ensino público no Brasil refletem os avanços e contradições que marcaram/marcam o caminho da democratização da sociedade brasileira.

\section{Referências}

ADRIÃO, T. Educação e produtividade: a reforma do ensino paulista e a desobrigação do Estado. São Paulo: Xamã, 2006.

ADRIÃO, T.; CAMARGO, R.B. A gestão democrática na Constituição Federal de 1988. In: OLIVEIRA, R. de O.; ADRIÃO, T. (Orgs). Gestão financiamento e direito à educação: análise da LDB e da Constituição Federal. 2. ed. São Paulo: Xamã, 2007, p.63 71 (Coleção Legislação e Política Educacional: textos introdutórios).

ARELARO, L.R.G. Resistência e submissão: a reforma educacional na década de 1990. In: KRAWCZYK, N.; CAMPOS, M.M.; HADDAD, S. O cenário educacional latinoamericano no limiar do século XXI: reformas em debate. Campinas: Autores Associados, 2000, p 95 - 116 (Coleção Educação Contemporânea).

BRASIL. Constituição Federal, 1988. Nacional.

Lei n. 9.394, de 20 de dezembro de 1996. Diretrizes e Bases para Educação

CHIAVENATO, I. Introdução à teoria geral da Administração. 3. ed. São Paulo: McGraw-Hill do Brasil, 1983.

COUTINHO, C.N. A democracia na batalha das idéias e nas lutas políticas do Brasil de hoje. In: FÁ VERO, O. SEMERARO, G. (Orgs.). Democracia e construção do público no pensamento educacional brasileiro. Petrópolis, RJ: Vozes, 2002.

CUNHA, L. A. ; GÓES, M. de. O golpe na Educação. $8^{\text {a }}$ edição. Rio de Janeiro: Zahar. 1994.

DRABACH, N. P. Primeiros Escritos sobre Administração Escolar no Brasil aos escritos sobre gestão escolar: mudanças e continuidade. 2009. 81f. Monografia (Especialização em Gestão Educacional) - Universidade Federal de Santa Maria, Santa Maria, 2009. 
GIORGI, C. Di. Escola Nova. 3. ed.. São Paulo: Editora Ática, 1992.

LEÃO, A. C. Introdução à Administração Escolar. 2. ed.. São Paulo: Companhia Editora Nacional, 1945.

LEDESMA, M. R. K. Gestão escolar: desafios dos tempos. 2008. 157f. Tese (doutorado em Educação) - Universidade Estadual de Campinas, Campinas, 2008.

LEMME, P. O Manifesto dos Pioneiros da Educação Nova e suas repercussões na realidade educacional brasileira. Revista Brasileira de Estudos Pedagógicos. Brasília. v.86, n.212, p.163-178, jan./abr., 2005.

LOURENÇO FILHO, M. B. Organização e Administração Escolar: curso básico. $8^{a}$ edição. Brasília: INEP/MEC, 2007.

PARO, V. H. O princípio da gestão escolar democrática no contexto da LDB. In: OLIVEIRA, R. P. de O.; ADRIÃO, T. (Orgs). Gestão financiamento e direito à educação: análise da LDB e da Constituição Federal. 2. ed. São Paulo: Xamã, 2007, p.7381 (Coleção Legislação e Política Educacional: textos introdutórios).

RIBEIRO, J. Q. Ensaio de uma teoria da Administração Escolar. São Paulo: Saraiva, 1986.

SALERNO, S.C.E.K. Administração gerencial ou gestão administrativa? Foco no planejamento educacional. 2006. 178 f. Tese (Doutorado em Educação) - Universidade Estadual de Campinas, Campinas, 2006.

SHIROMA, E.O. ; MORAES, M.C.M. ; EVANGELISTA, O. Política educacional. 4. ed. Rio de Janeiro: Lamparina, 2007.

SOUZA, A. R. De. Perfil da Gestão Escolar no Brasil. 2007. 302 f. Tese (Doutorado em Educação) - Programa de Pós-Graduação em Educação, Pontifícia Universidade Católica de São Paulo. São Paulo, 2007.

SOUZA, F.C. O ensino de História, a Lei de Diretrizes e Bases de 1971 e os Parâmetros Curriculares Nacionais (1998): continuidades e descontinuidades. In: ENCONTRO REGIONAL DA ASSOCIAÇÃO NACIONAL DE HISTÓRIA - ANPUH/PR, 11. Jacarezinho. Anais... Jacarezinho: UFPR, 2008, p.1-8.

TEIXEIRA, A. Que é administração escolar? Revista Brasileira de Estudos Pedagógicos. Bra ${ }^{9}$ sília. v. 36, n.84, p.84-89, 1961.

Recebido em novembro-12

Aprovado em maio-13 


\section{Notas}

${ }^{1}$ Mestranda em Políticas Educacionais no Programa de Pós Graduação em Educação da Universidade Federal do Paraná (UFPR). Bolsista Capes. E-mail: nadiadrabach@ yahoo.com.br

${ }^{2}$ A Escola Nova era um movimento de renovação escolar, cujas ideias "baseavam-se nos progressos mais recentes da psicologia infantil, que reivindicava uma maior liberdade para a criança, o respeito às características da personalidade de cada uma, nas várias fases de seu desenvolvimento, colocando o 'interesse' como o principal motor de aprendizagem [...] O centro da educação e da atividade escolar passava a ser a criança, com suas características próprias e seus interesses e não mais a vontade imposta do educador" (LEMME, 2005, p.167). Entretanto, este novo modelo pedagógico também despertou muitas críticas especialmente em relação ao desenvolvimento de um processo de psicologização da infância, pois, no processo educativo, eram consideradas apenas as características individuais e não as diferentes condições sociais dos indivíduos, o que contribuía para um agravamento das desigualdades. Além disso, promoveu uma adaptação da educação às demandas da sociedade capitalista, sem questionar a nova organização da sociedade a partir do processo de industrialização.

${ }^{3}$ Expressão de origem latina que significa "ao mesmo tempo", "simultaneamente". Nesta situação significa que o investimento na educação colocaria o Brasil em pé de igualdade com países desenvolvidos.

${ }^{4}$ A abordagem Clássica da Administração é composta por duas correntes que se desenvolveram no início do século XX, embora em contextos distintos: nos Estados Unidos a Escola de Administração Científica, tendo como principais expoentes Frederick Winslow Taylor (1856-1915) e Henry Ford (1863-1947); na França desenvolveu-se a Teoria Clássica, a partir dos trabalhos de Henri Fayol (1841-1925). A primeira corrente desenvolveu uma teoria administrativa com ênfase nas tarefas, enquanto a segunda a ênfase estava na estrutura. (CHIAVENATO, 1983).

${ }^{5}$ Vale lembrar que Sarney, na condição de vice-presidente e, contradizendo o princípio constitucional, que garantia a posse ao presidente da Câmara, assumiu o cargo no lugar de Tancredo Neves, presidente eleito, que faleceu antes da posse (SHIROMA; MORAES; EVANGELISTA, 2007).

6 É preciso salientar que as primeiras alterações na dinâmica da gestão da escola pública foram protagonizadas no Estado de São Paulo, com a instalação dos conselhos escolares em 1983. As alterações atendiam a demanda por democratização das relações de poder no interior da escola (ADRIÃO, 2006).

${ }^{7}$ O Estado de Bem Estar Social se expande no período de pós-guerra, nos anos de 1930, especialmente pela ação da classe trabalhadora e as inovações na política realizada pelos funcionários do Estado. "Naquele período, importantes países europeus já tinham consolidado elementos centrais do sistema de seguridade social: seguro contra acidente, auxílio-doença, previdência aos idosos e seguro-desemprego." (SALERNO, 2006, p.25). A autora destaca ainda que os sindicatos tiveram um papel muito importante na conquista dos Direitos Socais e na constituição do Estado de Bem Estar Social, no período industrial, que oferecia proteção ao trabalhador. No Brasil e na América Latina, no entanto, este tipo de Estado como rede de proteção organizada não chegou a se consolidar. Nos países de capitalismo periféricos, como é o caso do Brasil os serviços sociais adquiriram um caráter assistencialista e compensatório (SALERNO, 2006).

${ }^{8}$ Banco Mundial foi criado em 1944, durante a Conferência de Bretton Woods, bem como o Fundo Monetário Internacional e a Organização Mundial do Comércio. Estas instituições são portadoras de instrumento de intervenção e com capacidade para alterar decisões econômicas (SALERNO, 2006, NOTA). 